\title{
Fotografía y Memoria Histórica en la generación de la posmemoria
}

\section{Iván Cáceres Sánchez}

Coordinador de la Facultad de Artes Visuales y Creación Digital y Director de la Diplomatura en Creación Audivisual para Medios Digitales. Centro Universitario de Artes TAI, Madrid. Correo electrónico: ivancaceresart@ gmail.com. Tfno.: +34676344345.

\begin{abstract}
The purpose of this text is to link the concepts of posmemory with the photographic projects of two artists participating in Monte de Estépar exhibition, with a focus on the exhumation of the remains from mass graves of the Spanish Civil War in the region. The origin of the Platform of Antifascist Artists, organizers of this exhibition, will be explained after the controversy of Eugenio Merino in ARCO 2012. As a continuation, posmemory will be defined and similarities with photography as an artistic practice will be drawn and, by the end, two representative examples will be analized: Francesc Torres, a second-generation posmemorial artist with Oscura es la habitación donde vivimos, and Mario Santamaría, third-generation artist, with the project called Topografía de las fosas.
\end{abstract}

Keywords: Historical Memory, posmemory, Spanish Civil War, photography, contemporary art, Eugenio Merino, Monte de Estépar, Francesc Torres, Mario Santamaría

\begin{abstract}
Resumen
Este texto trata de vincular el concepto de posmemoria con los proyectos fotográficos de dos artistas participantes en la exposición Monte de Estépar, con motivo de las labores de exhumación de los restos procedentes de fosas comunes de la Guerra Civil Española en la región. Para ello se explicará el origen de la Plataforma de Artistas Antifascistas, organizadores de dicha exposición, tras la polémica de Eugenio Merino en ARCO 2012. A continuación se trazarán las líneas principales que definen el término posmemoria, relacionándolo con la fotografía como práctica artística, para, finalmente, presentar dos ejemplos representativos: Francesc Torres, artista posmemorial de segunda generación, con su proyecto Oscura es la habitación donde vivimos, y Mario Santamaría, de tercera generación, con el proyecto Topografía de las fosas.
\end{abstract}

Palabras clave: Memoria Histórica, posmemoria, Guerra Civil, fotografía, arte contemporáneo, Eugenio Merino, Monte de Estépar, Francesc Torres, Mario Santamaría 


\section{Introducción}

\subsection{Objetivos}

La Guerra Civil Española, en toda su complejidad y considerando las consecuencias desarrolladas durante un régimen de casi 40 años cuyos ecos aún resuenan en el escenario de la actualidad, está adquiriendo una creciente presencia en el panorama artístico nacional, donde numerosos y dispares proyectos abordan problemáticas derivadas del conflicto aún en viva discusión. Un denominador común de todos estos artistas es que constituyen un tejido creativo de "segunda y tercera generación", esto es, no han sido testigos directos de los acontecimientos pero sí poseen una suerte de "memoria cultural que apela [...] a una voluntad de reparación para con las víctimas de la guerra” (Quílez y Rueda, 2017, p. XIII), una relación de vínculo emocional particular constituida a partir del relato familiar y de retóricas procedentes de los distintos productos culturales que han tratado de representar el conflicto. Por ello, merece la pena revisitar la noción de posmemoria, tan fecundamente trabajada por algunos autores, especialmente Marianne Hirsch, a raíz del trauma de la Segunda Guerra Mundial y del Holocausto, analizando correspondencias y desencuentros con el caso de la Guerra Civil Española, epítome de la relación entre guerra y trauma en la historia particular de nuestro país. Este texto persiguie dos objetivos fundamentales: poner en relación el término posmemoria con las propuestas fotográficas de dos artistas que participaron en la exposición Monte de Estépar y, por otra parte, dar visibilidad a estos trabajos con la intención de ampliar el mapa sobre el estado de la cuestión de la Memoria Histórica en el ámbito de la fotografía española contemporánea.

\subsection{Always Franco}

La Feria de Arte Contemporáneo ARCO ha vuelto a ser este año, como viene siendo común en las últimas ediciones, foco de atención por parte de medios de difusión especializados y generalistas a raíz de la polémica suscitada por la obra escultórica titulada Ninot, una representación hiperrealista de cera, con 4 metros y medio de altura, del actual rey Felipe VI, cuya culminación y cierre de sentido se alcanzará cuando el posible comprador queme la efigie a modo de apoteosis final. La autoría de esta propuesta es, en esta ocasión, doble. Dos de los artistas más controvertidos del mercado artístico contemporáneo decidieron reunir para la ocasión, en una sola pieza, toda la carga política, sentido crítico y acidez que ya venían desarrollando a lo largo de sus respectivas carreras artísticas. Hablamos de Santiago Sierra y Eugenio Merino. Este último volvió a situarse en el punto de mira de la controversia artística y política en ARCO 2010, con su obra Stairway to Heaven, y en la edición de 2012, con la ya célebre propuesta titulada Always Franco, una pieza cargada una vez más de ironía, humor y crítica que consistía en una figura hiperrealista del uniformado dictador introducida dentro un refrigerador de Coca-Cola (Fig. 1). Esta "osadía” le valió a Eugenio Merino una demanda por parte de la Fundación Francisco Franco acusándole de "intromisión ilegítima en el honor” y que, finalmente, fue desestimada en 2013 por la jueza Rocío Nieto Centeno. A raíz de esta querella, un colectivo de artistas constituyeron la llamada Plataforma de Artistas Antifascistas, cuya primera acción mediática consistió en organizar en julio del mismo año las Jornadas Contra Franco: un evento para escarnio público de la figura del dictador, que tuvieron lugar en el conocido barrio madrileño de Vallecas. En este evento participaron artistas como Alejandro Jodorowsky, Francesc Torres, Isidoro Valcárcel Medina y los propios Santiago Sierra y Eugenio Merino, entre muchos otros. Uno de los momentos clave de estas jornadas fue la lectura de un manifiesto en apoyo al autor de Always Franco. 


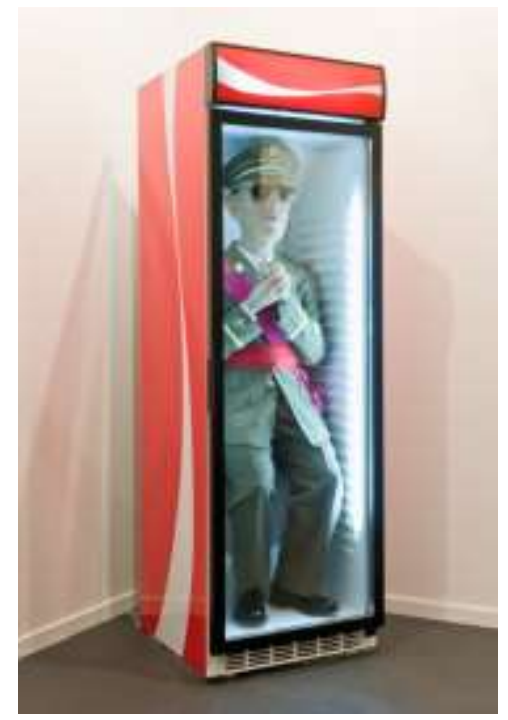

Fig.1 Fuente: Galería ADN (2012)

Como vemos, el caso de Eugenio Merino fue el desencadenante de acciones sucesivas donde la defensa de la libertad de expresión en todas sus formas artísticas se constituyó como eje fundamental. Otro hito destacable, y no tan mediático, en el desarrollo cronológico de la Plataforma de Artistas Antifascistas fue la realización de la exposición titulada Monte de Estépar (Fig. 2), que tuvo lugar en el Espacio Tangente en 2014, en colaboración con la Coordinadora por la Recuperación de la Memoria Histórica (CRMH) de Burgos. En paralelo se lanzó una campaña de micromecenazgo o crowdfunding destinada a financiar las excavaciones de las fosas comunes localizadas en Estépar y las exhumaciones de los restos de 96 víctimas hasta hoy recuperadas procedentes en su mayoría del Penal de Burgos (Carro, 2017). Aquellos donantes que participaron en la campaña, que alcanzó un total de $15.350 €$, pudieron recibir a cambio copias e incluso algún original de los artistas participantes en la exposición.

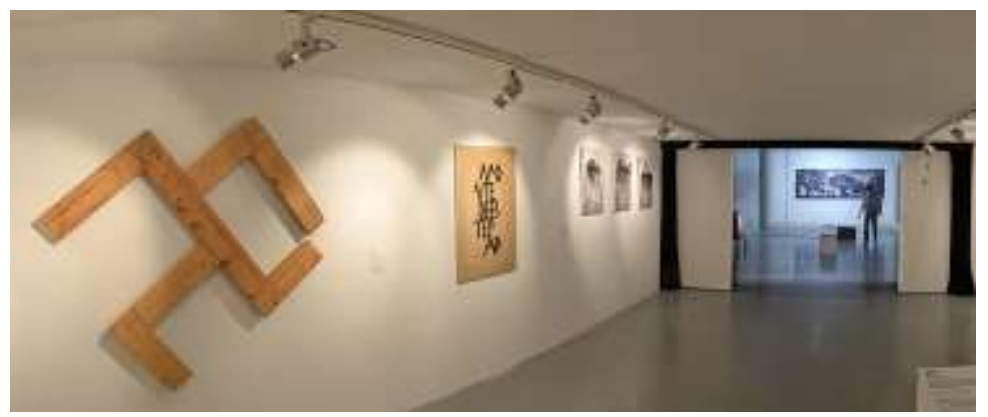

Fig.2 Fuente: Espacio Tangente (2014)

\section{Generación de la posmemoria}

\subsection{Pacto de olvido}

Este repunte de actividad artística enfocada en la recuperación de la Memoria Histórica no se trata de un fenómeno aislado ni anecdótico, sino que se inserta en una deriva socio-cultural donde se hace patente la necesidad de suturar una herida abierta desde el estallido de la Guerra Civil, pasando por la coda que fue la Transición, hasta nuestros días. En este proceso de reajuste, reconocimientos y afiliaciones han aflorado numerosos colectivos, entre los que destaca la Asociación para la Recuperación de la Memoria Histórica (ARMH), dedicados a cartografiar los escenarios donde tuvieron lugar matanzas y ejecuciones durante y después de la Guerra Civil, con el fin de recuperar los restos de los ejecutados y proceder a su identificación, normalmente con la colaboración cercana de los familiares. Uno de los grandes impulsos para el desarrollo de estas labores fue la aprobación hace 12 años de la ley 52/2007, popularmente conocida como Ley de la Memoria 
Histórica, que ha tenido una difícil aplicación en función de las dotaciones presupuestarias que los sucesivos gobiernos han ido destinando a ello.

Al parecer, la amnesia colectiva (André-Bazzana, 2006, p. 253) que trajo consigo la tabuización de la dictadura, poco a poco va diluyéndose y, al tiempo, consolidándose un reanálisis de la Transición, estableciendo líneas de responsabilidad y desmitificándola. Quizás, como indica Alejandro Baer cuando estudia la relación actual que los jóvenes alemanes muestran con el Holocausto, "en la nueva generación ha desaparecido la culpa personal y emergido una clara voluntad de asumir una responsabilidad política o moral colectiva" (Baer, 2006, p. 119), fruto de la desaparición de los custodios de la "memoria colectiva" (Chéroux, 2001, p. 221), es decir, los testigos directos del horror. El caso alemán, como vemos, se ha constituido como la medida de referencia para otros fenómenos de exterminio y traumas de guerra, vivido como un trauma transnacional y marcademente mediado por los productos culturales. Es común y relativamente reciente la tendencia de aplicar metodologías de análisis post-Holocausto al desarrollo de la Guerra Civil Española ya que la Shoah ha devenido finalmente "tropos universal" del genocidio (Huyssen, 2002, p. 17). La nueva estrategia que la historiografía debería tratar de abordar sería la de asumir que "toda lectura del pasado se hace desde una perspectiva personal que debe convivir, asimismo, con una pluralidad de puntos de vista diversos" (Quílez, 2014, p. 58). En este espacio de notable subjetividad, articulado por la experiencia individual a través de un trauma transmitido en el tiempo, es el punto de partida fundamental de muchos de los artistas de la posmemoria que han decidido romper el pacto de silencio y olvido.

\subsection{Posmemoria vs. rememoria}

Como apunta Marianne Hirsch de manera precisa, es necesario establecer una distinción entre dos maneras de afrontar un trauma a través de los distintos mecanismos de la memoria: la "rememoria" (término extraído de la novela de Toni Morrison Beloved) y la "posmemoria" (Hirsch, 2012, p. 118). A la reproducción del dolor traumático, trasnmitido de una generación a otra le corresponde el concepto de rememoria, es decir, la partícula re- haría alusión a la repetición, a una reaparición fantasmática de un trauma que no le es propio a quien ahora lo sufre, sino al testigo directo. La vivencia es transferida a una segunda o tercera generación poniendo en marcha complejos mecanismos de identificación, en primer término y, en segunda instancia, de transposición dentro del seno intrafamiliar. Sin embargo, para los artistas de la posmemoria el reto reside en crear una estética, donde quede patente la identificación, que pueda transmitir la memoria física de la guerra sin replicar el dolor traumático. Teniendo en cuenta la producción artística de los artistas posmemoriales como "representaciones" que ayuden a elaborar el trauma de la guerra podríamos considerar el re- del término representación como una partícula intensiva y no repetitiva (Nancy, 2006, p. 36). De la misma manera, el prefijo possignificaría "continuación de la memoria" y no "después de la memoria", o dicho de otra manera, una memoria extendida (Hirsch, 2012, p. 19).

Asimismo la autora distribuye el sentido de circulación de la posmemoria en dos direcciones, una posmemoria familiar, transmitida verticalmente entre una generación y otra, y una posmemoria afiliativa, en sentido horizontal o intrageneracional, facilitando a otros contemporáneos la identificación como hijo o nieto de superviviente. Una de las críticas más sonadas al discurso de Hirsch es la de Beatriz Sarlo, al considerar el termino posmemoria como innecesario puesto que, según la autora argentina, los mecanismos de mediación respecto al trauma no le son exclusivos, sino que están presentes en toda forma y manifestación de la memoria, independientemente de a qué generación pertenezca (Sarlo, 2005, p. 129).

\subsection{Fotografía y posmemoria: dos casos de estudio en Monte de Estépar}

Uno de los mayores potenciales que posee la fotografía, tanto ontológicamente como por su valor de uso, es el de vincular ambas tipologías de posmemorias (Hirsch, 2012, p. 63). El archivo familiar constituye una de las principales fuentes de transmisión y un reducto inestimable para la memoria, actuando como mediador y escudo frente al trauma. Una de las discusiones más fructíferas al respecto de la fotografía como registro de realidad surge al identificar un desplazamiento mediante el cual la indexicalidad que se le presuponía al medio fotográfico en primera instancia pasa a adquirir un marcado sentido simbólico (Didi-Huberman, 2004, p. 32), especialmente en la generación de artistas posmemoriales. La lectura de las fotografías de la memoria deviene, en estos casos, tremendamente subjetiva, vehículada por medio de la emotividad y afectación del individuo, por el punzamiento barthesiano que traspasa la imagen. 
Sorprendentemente encontramos escasos proyectos con formalización fotográfica en la exposición Monte de Estépar, quizás porque desconfiamos de las imágenes al ser separadas de su fenomenología cuando las relegamos a la esfera del documento (2004, p. 59). Sea como fuere, podemos encontrar dos ejemplos fotográficos significativos inscritos en el mismo evento expositivo que abordan la recuperación de la Memoria Histórica desde posiciones prácticamente antagónicas, aunque con algun punto en común. A continuación se mostrarán brevemente las propuestas de dos artistas posmemoriales pertenecientes a la segunda y tercera generación respectivamente: Francesc Torres y Mario Santamaría.

\subsubsection{Francesc Torres: Oscura es la habitación donde dormimos}

Oscura es la habitación donde dormimos es de un proyecto compuesto por dos instalaciones y un fotolibro (que fue la pieza expuesta en Burgos) donde quedan recopiladas las imágenes y textos que componen el proyecto. Partiendo de los trabajos de exhumación de los restos humanos de una fosa común en Villamayor de los Montes (Burgos), en colaboración con la ARMH, el artista catalán nacido en 1948 documenta todo el proceso de excavación, catalogación e identificación a través de fotografías en un riguroso blanco y negro. Francesc Torres se centra en los rostros de aquellos vecinos y voluntarios gracias a los cuales el trabajo pudo salir adelante, además de prestar especial atención a los detalles y objetos encontrados junto a los restos humanos. Son imágenes de notable densidad y nitidez que, a la manera de detectives o arqueólogos, pretenden escudriñar cada detalle del terreno, no dejando lugar a desenfoques ni imprecisiones que un obturador demasiado abierto causaría (Fig. 3). Este afán por mostrar el detalle viene potenciado por el formato de las imágenes impresas en su versión expositiva. Se trata de ampliaciones que alcanzan los 2 metros en algunos casos. Gracias a la ausencia de color el espectador puede fijarse con más atención en las formas y texturas del suelo, desde donde emergen los restos. Los huesos y objetos allí encontrados pertenecían a 46 varones que fueron ejecutados el 24 de septiembre de 1936 y enterrados por las milicias falangistas. En las 29 fotografías que constituyen la instalación fotográfica, autodefinida como una suerte de diario visual, se ven implicados familiares de las víctimas a las cuales se les entregaron los restos además de mostrarse el entierro en el cementerio del pueblo a modo de conclusión. Nos encontramos ante un proyecto donde la cámara se comporta como un instrumento de prospección más, evidenciando que nos encontramos en un contexto donde la máquina, el artefacto, es el medio mediante el cual se puede desvelar aquello que estaba oculto y silenciado. Las imágenes, con cierta atmósfera dramática, se situán en un espacio tensional comprendido entre un largo silencio pesado y el desgarrador llanto, horror y descarga emocional a partes iguales, que permanece latente en los rostros del pasado y del presente. Esta serie de fotografías despliegan una intensa pregnancia en la memoria, adoptando en ocasiones estéticas de archivo, cohesionadas por el trasfondo de una memoria familiar y, a la vez, una memoria de amplitud colectiva.

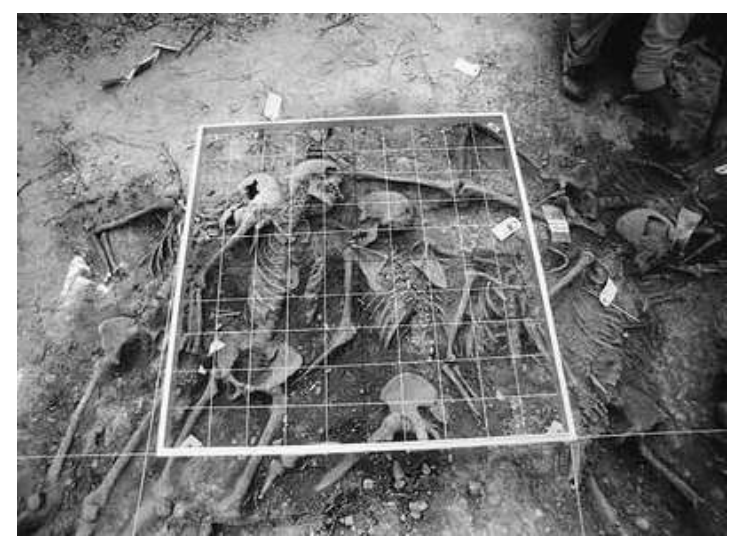

Fig.3 Fuente: The Guardian (2007)

\subsubsection{Mario Santamaría: Topografía de las fosas}

Mario Santamaría, artista nacido en 1985, propone un ejercico fotográfico enmarcado dentro de las prácticas posfotográficas de apropiación en el que se nos muestran 347 capturas de imagen (Fig. 4) procedentes de fotografías aéreas tomadas por el satélite de la compañía Google recopiladas en una página web creada ex profeso (http://valledeloscaidos.org). Se trata de un estudio del terreno a lo largo y ancho de todo el territorio nacional titulado Topografías de las fosas. En este caso se ponen en cuestión distintas problemáticas como son la noción de autoría, la 
apropiación y el arte informático, sin embargo, son asuntos que merece la pena tratar en otra ocasión ya que exigiría un espacio de discusión tremendamente más amplio de lo que este texto puede ofrecer. Nos centraremos, pues, en la vinculación que estas imágenes poseen con la recuperación de la Memoria Histórica. Si bien Topografía de las fosas coloca el foco en las particularidades y variedades del terreno, también manifiesta una patente ambigüedad, la de la distancia emocional y ausencia de un operator fotográfico con el que establecer una línea empática y, a su vez, la oscura historia que tiñe la tierra que observamos desde una altura infinita cuyos testigos y herederos de la memoria quedan reducidos a una escala invisible. El espectador adopta un punto de vista omnisciente, alejado de todo rostro, nombre o etiqueta. Las imágenes se nos presentan como una cuadrícula interminable en una página web (soporte virtual que acentúa la distancia y desconexión con el acontecimiento real) desprovista de texto y de cualquier otra indicación, salvo el título de la URL "valledeloscaídos" como una referencia demasiado evidente. Cada imagen-tesela pierde su carácter individual y adopta un valor de unidad dentro de un conjunto mucho mayor, un mosaico donde los elementos que, en un principio, eran identificables quedan ahora reducidos a valores de tonalidad, color, forma y textura, cercanos a la abstracción. La estrategia que Mario Santamaría ha decidido tomar es la de desbordar al espectador por la densidad de imágenes y una sensación de acumulación voraz. Solo es a posteriori, tras una pausa, cuando el espectador es consciente de que cada imagen corresponde a una fosa común y es entonces cuando adquiere una idea aproximada de la magnitud de esta problemática.
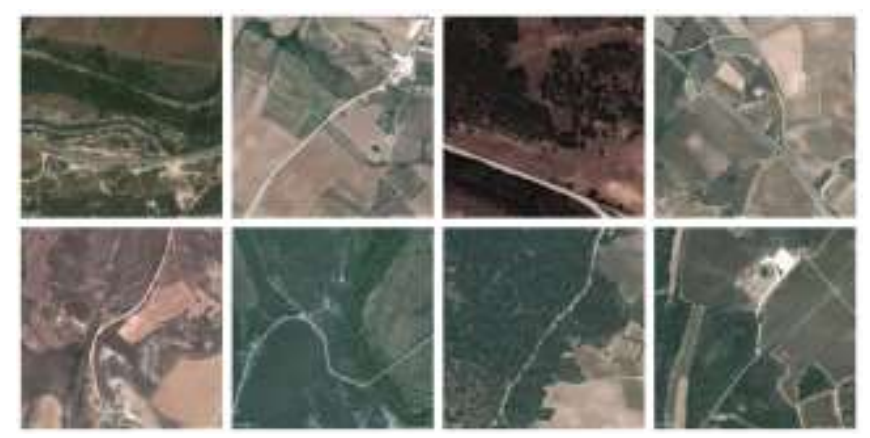

Fig.4 Fuente: Google (2014)

\section{Conclusiones}

Tras analizar el florecimiento, por un lado, de colectivos dedicados a la recuperación de la Memoria Histórica, y por otro, de agrupaciones de artistas con una fuerte carga política en relación a la Guerra Civil Española y sus capítulos posteriores, podemos darnos cuenta de que hay un capítulo que abarca casi medio siglo en nuestra historia reciente que no está debidamente clausurado. Las peticiones de reconocimiento de víctimas y verdugos vuelven a cobrar absoluta vigencia, desarrollándose en un ámbito de polarización política e ideológica al que el mundo de las artes, y en concreto el de la fotografía, no es ajeno. El contexto democrático actual ha devenido un espacio donde las dialécticas que se establecen parten de puntos cada vez más alejados entre si, radicalizándose en forma y fondo. Por ello, no es concebible continuar, al menos en lo que a asuntos de Memoria Histórica se refiere, desde posicionamientos amparados en sentimientos de venganza que resuciten la brecha del trauma. Como indica Marianne Hirsch a la hora de afrontar el trauma de la Historia, sería deseable realizar una "lectura reparadora" y no así "una lectura paranoica" (Hirsch, 2012, p. 109), esto es, no perpetuar el trauma por medio de la repetición compulsiva de familiares sospechas, sino elaborarlo e integrarlo por medio de un proceso de posmemoria y no de rememoria. Así pues, los distintos productos culturales, en tanto en cuanto mediadores de la posmemoria, tienen la responsabilidad (o más bien sus artífices) de promover esta mirada reparadora a través de nuevas narrativas que pongan atención en las historias individuales, particulares, huyendo de los grandes y fallidos relatos que se han nutrido tradicionalmente de una excesiva simplificación. Ya hemos señalado la deriva política de gran parte de propuestas que ocupan hoy espacios hegemónicos del arte. Si bien no es un hecho absolutamente nuevo, merece la pena tenerlo en cuenta como síntoma de una afección mucho más extendida.

Debido a esto, conviene reivindicar de nuevo la figura del testigo de segunda y tercera generación, portador de una memoria extendida en el tiempo que pueda servir de inestimable herramienta para generar nuevos relatos y maneras de 
afrontar un pasado traumático. Como se ha indicado en el texto, los artistas posmemoriales han de reclamar su especificidad como custodios de la memoria ahora que los testigos directos están desapareciendo de manera tanto natural como inevitable. A pesar de las críticas que este neologismo ha sufrido, la posmemoria puede ser un elemento dinamizador dentro de los discursos contemporáneos acerca de la recuperación de la Memoria Histórica y la visibilización del pasado enterrado por los pactos de olvido. Por otra parte, el hecho de que numerosos proyectos insistan en el titánico trabajo que aún queda por realizar en cuanto a localización, apertura de fosas, recuperación de restos e identificación, nos indica que la clausura del trauma de la Guerra Civil está aún lejos de alcanzarse.

Por último, es interesante prestar atención a las diferencias existentes, frecuentemente, entre artistas de segunda y tercera generación después del conflicto armado. Los primeros suelen poner atención a los testigos directos de la guerra, por evidente proximidad y familiaridad. Cuando nos referimos a testigos directos hablamos tanto de personas como de paisajes, archivos de imágenes y arquitecturas. Algunos de estos mejores ejemplos los encontramos en Ana Teresa Ortega, Gervasio Sánchez y el propio Francesc Torres. Sin embargo, los artistas posmemoriales de tercera generación llevan a cabo más comúnmente otro tipo de prácticas que huyen de la imagen fotográfica, ya sea por desconfianza de ésta como portadora de verdad o por la sobreexplotación de las mismas imágenes del horror que una y otra vez están presentes en productos culturales de amplia difusión. Estos artistas, en su mayoría nacidos en los años 70 y 80, apuestan por la intervención sobre la imagen de archivo o la total descontextualización de esta, observándose además propuestas fuertemente condicionadas por los mass media.

\section{Referencias}

André-BazZana, B. (2006). Mitos y mentiras de la Transición. Madrid: El Viejo Topo.

BAER, A. (2006). Holocausto. Recuerdo y representación. Madrid: Losada.

CARro, P. (2017). "La inhumación de 96 cuerpos de represaliados cierra un círculo de dolor y duelo en Estépar" en Burgosconecta, 7 de octubre de 2017. <https://www.burgosconecta.es/2017/09/30/la-inhumacion-de-96-cuerpos-de-represaliados-cierra-un-circulode-dolor-y-duelo-en-estepar.html> [Consulta: 10 de septiembre de 2019].

ChÉRoux, C. (dir.) (2001). Mémoire des Camps, photographies des camps de concentration et d'extermination Nazis (1933-1999). París: Marval.

Didi-Huberman, G. (2004). Imágenes pese a todo: memoria visual del Holocausto. Barcelona: Paidós Ibérica.

ESPACiO TANGENTE. Monte de Estépar.<http://montedeestepar.org/>. [Consulta: 12 de septiembre de 2019].

---. “Contra Franco" en Artistas Antifascistas blog. <https://artistasantifascistas.wordpress.com/2013/06/09/156/>. [Consulta: 12 de septiembre de 2019].

HIRSCH, M. (2012). La Generación de la posmemoria. Escritura y cultura visual después del Holocausto. Madrid: Carpe Noctem.

Huyssen, A. (2002). En busca del futuro perdido. Cultura y memoria en tiempos de globalización. México: Fondo de cultura económica.

NANCY, J. L. (2006). La representación prohibida. Seguido de La Shoa, un soplo. Buenos Aires: Amorrortu.

Quílez, L. (2014). "Hacia una teoría de la posmemoria. Reflexiones en torno a las representaciones de la memoria generacional” en Historiografías, 8, 57-75. <http://www.unizar.es/historiografias/numeros/8/quilez.pdf> [Consulta: 2 de septiembre de 2019].

Quílez, L. y RuEDA, J. C. (eds.) (2017). Posmemoria de la Guerra Civil y el Franquismo. Narrativas audiovisuales y producciones culturales en el siglo XXI. Granada: Comares.

SANTAMARía, M. Valle de los caídos. 〈http://www.valledeloscaidos.org/>. [Consulta: 12 de septiembre de 2019].

SARLO, B. (2005). Tiempo pasado. Cultura de la memoria y giro subjetivo. Una discusión. Buenos Aires: Siglo XXI.

TORRES, F. (2007). Oscura es la habitación donde dormimos. Barcelona: ACTAR. 